\title{
CORRESPONDENCE
}

\section{How to treat children's pneumonia: a complex problem}

\section{To the Editors:}

We read with great interest the analysis of cost minimisation in the treatment of paediatric community-acquired pneumonia (CAP) by LORGELLY et al. [1] in the current issue of the European Respiratory Journal. The analysis was based on the randomised controlled non-blinded multicentre equivalence trial (PIVOT study), in which oral amoxicillin and intravenous benzyl penicillin had equivalent efficacy in the treatment of CAP in 246 children admitted to hospital [2]. The median time for temperature to be $<38^{\circ} \mathrm{C}$ for $24 \mathrm{~h}$ was 1.23 days in the intravenous penicillin group and 1.30 days in the oral amoxicillin group [2]. The median in-patient stay was significantly shorter in the oral amoxicillin group than in the intravenous penicillin group (1.77 versus 2.10 days, respectively). The PIVOT study did not take into account the aetiology or severity of CAP, or the age of the patients. The high levels of nonspecific inflammation markers suggested that most patients had either bacterial or mixed viral-bacterial CAP. Children with complicated pneumonia, such as those with oxygen saturation $<85 \%$, shock requiring fluid resuscitation or pleural fluid requiring drainage, were excluded [2].

The cost-minimising analysis included 232 children with sufficient economical data available, and considered the costs for the health service, families and society (societal perspective) until the child was fully recovered. Treatment with intravenous penicillin was more expensive and led to a longer mean inpatient stay than treatment with oral amoxicillin (3.12 versus 1.93 days, respectively; $\mathrm{p}<0.001$ ) [1]. From a statistical point of view, the difference favouring oral amoxicillin, calculated by mean (1.19 days), was more than in the original analysis, calculated by median (0.33 days) [2]. On average, the overall costs in the oral amoxicillin treatment group were $61.2 \%$ of those in the intravenous penicillin treatment group (95\% CI 40.3-81.4).

We have recently published our results on the aetiology [3], severity [4] and clinical picture [5] of radiologically diagnosed CAP in 101 children treated as in-patients or outpatients. We performed a secondary analysis to evaluate the improvement of the patients. Body temperature was measured four times a day in hospital and twice a day at home after discharge. If primarily treated at home, the parents were contacted by phone $48-72 \mathrm{~h}$ after starting antibiotics. The treatment was selected on clinical grounds by the doctors on duty, and the recommended drugs were oral amoxicillin in mild-to-moderate cases and intravenous ampicillin in severe cases. Cephalosporins or macrolides were recommended for children with penicillin allergy. Body temperature data were available in 94 children, and among them: 59 received amoxicillin orally as the first-line drug, 21 received ampicillin intravenously, and 14 received other antibiotics (including cephalosporins in eight cases and macrolides in four cases). The mean (range) hospitalisation time was 5 (3-13) days in the 25 subjects treated as in-patients.
After starting antibiotics, the mean \pm SD duration of fever was $23.0 \pm 19.2 \mathrm{~h}$, being $15.6 \pm 13.4 \mathrm{~h}$ in children $<2 \mathrm{yrs}$ of age, $18.9 \pm 14.9 \mathrm{~h}$ in children aged $2-4 \mathrm{yrs}$ and $31.2 \pm 23.1 \mathrm{~h}$ in children aged $>5$ yrs $(p=0.003)$. Fever decreased in $44(47 \%)$ children within $12 \mathrm{~h}$, in 25 (27\%) between 13-24 h, in 21 (22\%) between $25-48 \mathrm{~h}$ and in only four (4\%) children after $48 \mathrm{~h}$. Clinical signs [5] or serological findings [3] had no association with the duration of fever. As the only exception, high respiratory rate was associated with short duration of fever. Like the PIVOT study, children with wheezing were excluded [2]. Nonspecific inflammatory markers studied on admission had an inverse association with the duration of fever in ageadjusted linear regression: erythrocyte sedimentation rate $(\beta=-0.204, p<0.001)$, procalcitonin $(\beta=-0.261, p=0.031)$, white blood cells $(\beta=-0.000, p=0.053)$ and $C$-reactive protein $(\beta=-0.038, p=0.050)$. The duration of fever was shorter in the intravenous ampicillin $(13.4 \pm 11.3 \mathrm{~h})$ than in the oral amoxicillin group $(25.2 \pm 18.6 \mathrm{~h}, \mathrm{p}=0.012$ in non-adjusted and $\mathrm{p}=0.002$ in age-adjusted analyses). When two children with empyema were excluded, the mean (range) duration of intravenous ampicillin administration was 3.3 (1-7) days, which is more than the average duration of 1.5 days in the British study [2].

The results of this pragmatic secondary analysis gave evidence that a treatment modality for CAP of starting antibiotics intravenously and continuing orally may be more effective than oral treatment alone in hospitalised children with presumably bacterial pneumonia. The aim of the study was not to compare the treatment modalities, as antibiotics were chosen by the doctors on duty on their clinical consideration. Thus, the results suggest that those patients, with more severe disease, who would have benefited from intravenous treatment, were allocated to the right group. A successful and rational choice between the treatment modalities (intravenous antibiotics in severe bacterial infections and oral antibiotics in mild-to-moderate bacterial infections) is also the most costeffective. To increase cost-effectiveness, the times for intravenous treatment (on average, 3.3 days versus 1.5 days in the PIVOT study) and the hospital stay (on average 5 days versus 2-3 days in the PIVOT study) should be shortened. We appreciate the cost-minimising analysis [1], which considerably diversifies the information obtainable from the PIVOT study. Future studies on the treatment of CAP in children should be, as often as possible, supplemented by costeffectiveness analyses but and aetiology, severity of CAP and age of the children should be taken into account.

\section{Don* and M. Korppi ${ }^{*}$}

*Paediatric Dept, School of Medicine, DPMSC, University of Udine, Udine, Italy, and "Paediatric Research Centre, Tampere University and University Hospital, Tampere, Finland. 
Correspondence: M. Don, Paediatric Dept, Allergology and Pulmonology Unit, School of Medicine DPMSC, University of Udine, P.le S. Maria della Misericordia, 33100 Udine, Italy. E-mail: max.don@libero.it

Statement of Interest: None declared.

\section{REFERENCES}

1 Lorgelly PK, Atkinson M, Lakhanpaul M, et al. Oral versus i.v. antibiotics for community-acquired pneumonia in children: a costminimisation analysis. Eur Respir J 2010; 35: 858-864.

2 Atkinson M, Lakhanpaul M, Smyth A, et al. Comparison of oral amoxicillin and intravenous benzyl penicillin for community acquired pneumonia in children (PIVOT trial): a multicentre pragmatic randomised controlled equivalence trial. Thorax 2007; 62: 1102-1106.

3 Don M, Fasoli L, Paldanius M, et al. Aetiology of communityacquired pneumonia: serological results of a paediatric survey. Scand J Infect Dis 2005; 37: 806-812.

4 Don $\mathrm{M}$, Valent F, Korppi M, et al. Efficacy of serum procalcitonin in evaluating severity of community-acquired pneumonia in childhood. Scand J Infect Dis 2007; 39: 129-137.

5 Korppi M, Don M, Valent F, et al. The value of clinical features in differentiating between viral, pneumococcal and atypical bacterial pneumonia in children. Acta Paediatr 2008; 97: 943-947.

DOI: $10.1183 / 09031936.00170809$

\section{Endocrinological derangement in COPD}

\section{To the Editors:}

With the greatest interest I have read the comprehensive review "endocrinological derangements" in chronic obstructive pulmonary disease (COPD) by LAGHI et al. [1]. Arriving at the last page, where the authors discussed the reninangiotensin-aldosterone system, I have read: "the presence of sympathetic neuropathy..." and "...the possibility that autonomic neuropathy is caused by intraneural hypoxaemia".

In COPD and other diseases such as heart failure and obstructive sleep apnoea the concept of autonomic nervous system dysbalance with increased sympathetic activation and reduced parasympathic activity has been recognised [2-6]. Recent work published in this journal on normoxic COPD patients demonstrated that slow breathing reduces sympathoexcitation and improves baroreflex sensitivity, raising possible therapeutic implications concerning the autonomic nervous system [7]. There is a strong mutual interaction between angiotensin and the sympathetic nervous system [8]. This interaction may partly account for the activation of the renin-angiotensin-aldosterone system LAGHI et al. [1] competently described in COPD patients.

Interestingly, work published in the same volume as the review on endocrinological derangements in COPD demonstrated marked alterations in cardiac autonomic control in patients with pulmonary artery hypertension [4]. The authors and an adjoining editorial discussed various causes of the observed findings, such as sympathetic overactivity related to an overactive chemoreflex and baroreflex, increased filling pressure and blood gas alterations $[4,6]$.

Thus, there is growing evidence demonstrating a dysfunction of the autonomic nervous system in COPD patients [2]. This evidence stems from evaluating the baroreflex sensitivity, heart rate variability and muscle sympathetic nerve activity, and is corroborated by research on other diseases such as heart failure, sleep apnoea and pulmonary hypertension $[3,6]$. This evidence can not be readily explained by intraneuronal hypoxaemia. However, in very severe COPD patients and long-standing severe hypoxaemia without supplemental oxygen alterations of the peripheral nervous system may ensue.

\section{S. Andreas}

Ärztlicher Leiter, Lungenfachklinik Immenhausen/Kr. Kassel, Pneumologische Lehrklinik Universität Göttingen, Immenhausen, Germany.

Correspondence: S. Andreas, Ärztlicher Leiter, Lungenfachklinik Immenhausen/Kr. Kassel, Pneumologische Lehrklinik Universität Göttingen, Robert-Koch-Str. 3, 34376 Immenhausen, Germany. E-mail: sandreas@lungenfachklinik-immenhausen.de

Statement of Interest: None declared.

\section{REFERENCES}

1 Laghi F, Adiguzel N, Tobin MJ. Endocrinological derangements in COPD. Eur Respir J 2009; 34: 975-996.

2 Andreas S, Anker SD, Scanlon PD, et al. Neurohumoral activation as a link to systemic manifestation of chronic lung disease. Chest 2005 128: 3618-3624.

3 Floras JS. Clinical aspects of sympathetic activation and parasympathetic withdrawal in heart failure. J Am Coll Cardiol 1993; 22: Suppl. A, 72a-84a.

4 Wensel R, Jilek C, Dorr M, et al. Impaired cardiac autonomic control relates to disease severity in pulmonary hypertension. Eur Respir $J$ 2009; 34: 895-901.

5 Andreas S, Eichele G. Sleep apnoea: time to consider clock genes. Eur Respir J 2008; 32: 1-2.

6 Naeije R, van de Borne P. Clinical relevance of autonomic nervous system disturbances in pulmonary arterial hypertension. Eur Respir $J$ 2009; 34: 792-794.

7 Raupach T, Bahr F, Herrmann P, et al. Slow breathing reduces sympathoexcitation in COPD. Eur Respir J 2008; 32: 387-392.

8 Reid IA. Interactions between ANG II, sympathetic nervous system, and baroreceptor reflexes in regulation of blood pressure. Am J Physiol 1992; 262: E763-E778. 